\title{
A Battery Life Extension System Based on a Bidirectional DC Power Converter for Uninterruptible Power Systems
}

\author{
Wen-Chih Yang, Yi-Kuan Lin, Yu-Jen Hsu \\ Department of Electrical Engineering \\ Taipei City University of Science and Technology \\ Taiwan, R.O.C.
}

\begin{abstract}
A battery life extension system for uninterruptible power systems is proposed in this paper. The proposed system consists of a bidirectional DC power converter, voltage sensors, current sensors, a microcontroller and a supercapacitor bank. It allows the batteries and the supercapacitor bank in uninterruptable power systems to charge and discharge each other periodically. Therefore, the energy storage materials of the batteries in uninterruptible power systems can be activated, and then the life time of the batteries can be extended effectively. In this paper, the topology and the operating principle of the proposed battery life extension system are introduced first. The test results are then presented and discussed in detail.
\end{abstract}

Keywords-Uninterruptible power system, bidirectional DC power converter, supercapacitor, battery.

\section{INTRODUCTION}

An uninterruptible power system (UPS) is an emergency backup power source. It can provide backup electric power to major electric equipment of users in a short time when power utilities' power grids lose power [1]. UPSs are essential devices for users. They nowadays are very popular for the financial, electronics, communications, information and medical industries [2].

The energy storage component of a UPS is a battery. UPSs' batteries are fully charged at all times for providing emergency backup power to their loads during a grid outage. UPSs' batteries are rarely discharged because the power grid has few power outages. So that the energy storage materials of the batteries gradually lose their activity $[3,4]$. Under this situation the storage capacities of UPSs' batteries are reduced and their life time are shortened. Moreover, the waste batteries will increase and this problem will affect the environment protection.

To solve the above problem, the easiest way is to discharge the UPSs' batteries regularly because the discharge can activate the energy storage materials of the batteries. The conventional discharge method for UPSs' batteries is called the load discharge method [5]. This method allows UPSs' batteries to periodically discharge their loads, and then recharge the batteries after the discharge work. Figure 1 shows the schematic diagram of the load discharge method. There are two shortcomings for this method. One is to waste electric power, and the other is to interfere with the function of providing emergency power supply of UPSs. For improving the shortcomings, a battery life extension system (BLES) based on a bidirectional DC power converter is developed by this research. The developed system allows the UPSs' batteries and a supercapacitor bank to periodically charge and discharge each other. In this way, the energy storage materials of UPSs' batteries can be activated effectively and the shortcomings of load discharge method can be solved.

In this paper, the topology of the proposed BLES is introduced first. The proposed BLES consists of a bidirectional DC power converter, voltage sensors, current sensors, a microcontroller and a supercapacitor bank. The operating principle of the bidirectional DC power converter is introduced here. Two test cases have carried out to examine the performance of the proposed BLES. The test results of the two cases are then presented and discussed in detail.

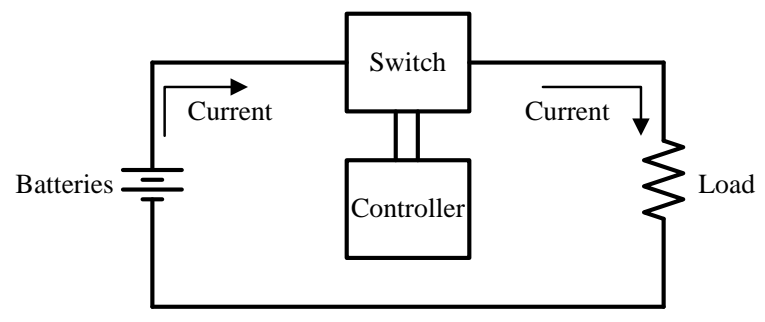

Fig. 1. Schematic diagram of the load discharge method.

\section{TOPOLOGY OF THE DEVELOPED BELS}

Fig. 2 shows the block diagram of a conventional off-line UPS. Conventional UPSs use the load discharge method to discharge their batteries [6]. Their circuit architecture is simple. In order to overcome the shortcomings of the load discharge method, the developed BLES is connected in series before the batteries of a UPS, as shown in Fig. 3. The developed BLES consists of a bidirectional DC power converter, a microcontroller, voltage sensors, current sensors and a supercapacitor bank. Its topology is shown in Fig. 4..

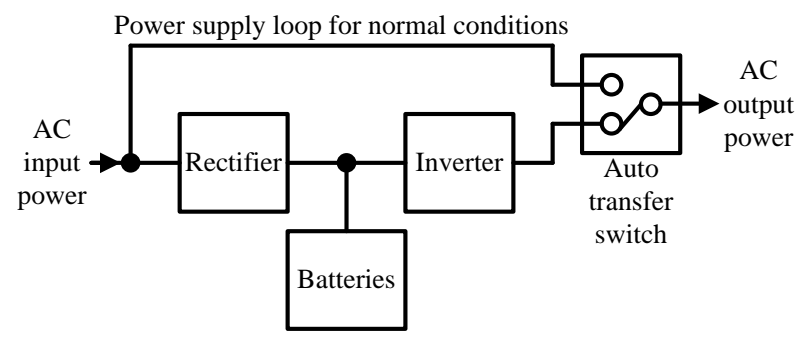

Fig. 2. Block diagram of a conventional off-line UPS. 


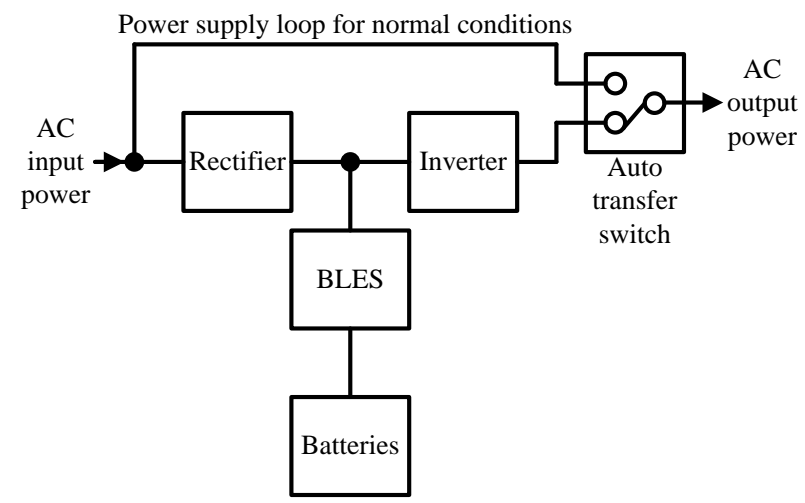

Fig. 3. Block diagram of a conventional off-line UPS with the developed BLES.

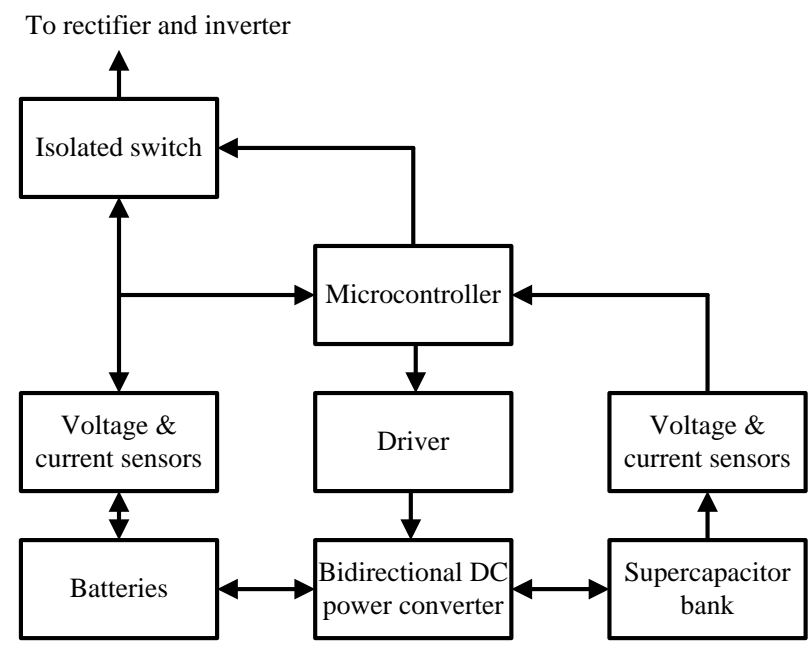

Fig. 4. Topology of the developed BLES.

\section{OPERATING PRINCIPLE OF A BIDIRECTIONAL DC POWER CONVERTER}

Fig. 2 shows the circuit of a bidirectional DC power converter which is based on a half-bridge power conversion topology [7]. The $\mathrm{Q}_{1}$ and $\mathrm{Q}_{2}$ are n-channel MOSFETs with a parasitic diode $D_{1}$ and $D_{2}$, respectively. The two n-channel MOSFETs are used as switches. The gate poles of $\mathrm{Q}_{1}$ and $\mathrm{Q}_{2}$ are connected to its driver $\mathrm{DR}_{1}$ and $\mathrm{DR}_{2}$, respectively. The inductor $\mathrm{L}$ is an energy storage component. The supercapacitor bank $\mathrm{C}$ is connected to the inductor $\mathrm{L}$ and then the batteries B are connected to the MOSFET $\mathrm{Q}_{1}$ and $\mathrm{Q}_{2}$.

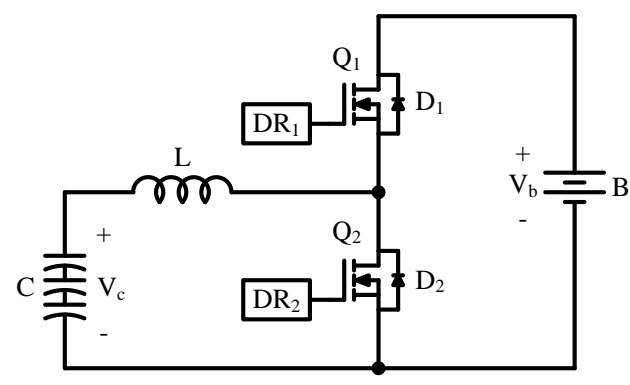

Fig. 5. The topology of a bidirectional DC power converter used in the developed BLES

The operating principle of the bidirectional DC power converter is described bellow $[5,6]$.
1) Mode 1:

Fig. 6 shows the equivalent circuit of the bidirectional DC power converter when operating in mode 1 . In this mode, the MOSFET $\mathrm{Q}_{1}$ is turned on by the driver $\mathrm{DR}_{1}$ and the MOSFET $\mathrm{Q}_{2}$ is turned off by the driver $\mathrm{DR}_{2}$. Therefore, the bidirectional DC power converter acts a buck conversion circuit. A current I flows from the batteries B to the supercapacitor bank $\mathrm{C}$. The batteries B charges the supercapacitor bank C. Under this situation, the batteries $\mathrm{B}$ are discharged and the supercapacitor bank $\mathrm{C}$ is charged. The energy in the batteries $\mathrm{B}$ is transferred to the supercapacitor bank $\mathrm{C}$. The current I also flows through the inductor L. Therefore, some energy is storage in the inductor $\mathrm{L}$.

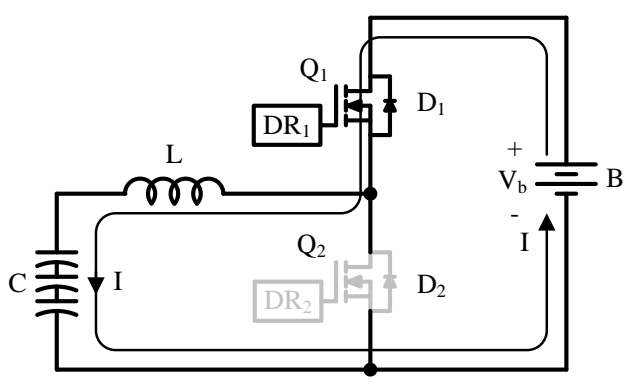

Fig. 6. The equivalet circuit of the bidirectional DC power converter when operating in mode 1 .

\section{2) Mode 2:}

Fig. 7 shows the equivalent circuit of the bidirectional DC power converter when operating in mode 2 . In this mode, the MOSFETs $Q_{1}$ and $Q_{2}$ are turned off by the driver $D_{1}$ and $\mathrm{DR}_{2}$, respectively. The inductor $\mathrm{L}$ releases its energy during this mode. Therefore, the current I flows into the supercapacitor bank $\mathrm{C}$ via the parasitic diode $\mathrm{D}_{2}$. That means the inductor L charges the supercapacitor bank $\mathrm{C}$. Under this situation, the voltage of the supercapacitor bank $\mathrm{C}$ will rise continuously.

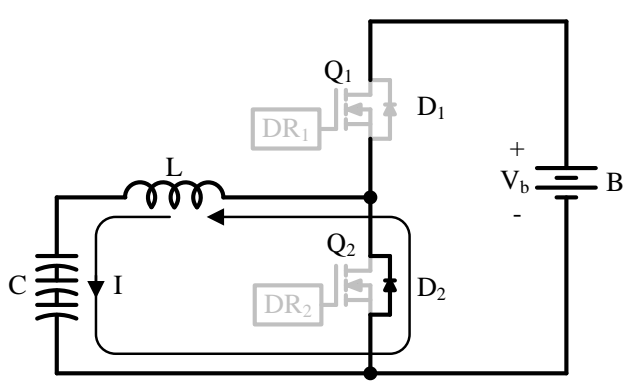

Fig. 7. The equivalet circuit of the bidirectional DC power converter when operating in mode 2 .

3) Mode 3:

Fig. 8 shows the equivalent circuit of the bidirectional DC power converter when operating in mode 3 . In this mode, the MOSFET $\mathrm{Q}_{1}$ is turned off by the driver $\mathrm{DR}_{1}$ and the MOSFET $\mathrm{Q}_{2}$ is turned on by the driver $\mathrm{DR}_{2}$. A current I flows from the supercapacitor bank $\mathrm{C}$ to the inductor $\mathrm{L}$ via the MOSFET $\mathrm{Q}_{2}$. That means the energy in the supercapacitor bank $\mathrm{C}$ is transferred to the inductor $\mathrm{L}$. In this mode, the MOSFET $\mathrm{Q}_{1}$ is turned off. The voltage level of the batteries B is larger than the supercapacitor bank B. Therefore, the current I can not flow into the batteries $\mathrm{B}$ via the parasitic diode $\mathrm{D}_{1}$. 


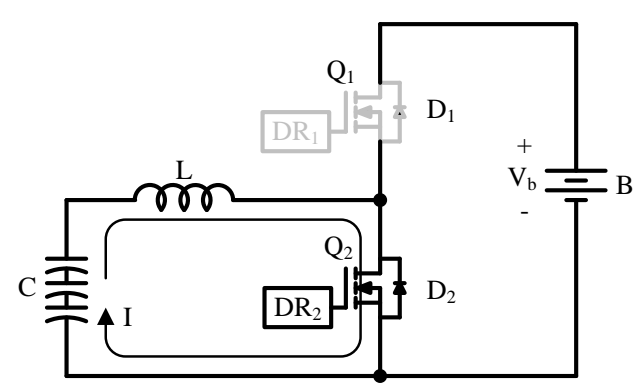

Fig. 8. The equivalet circuit of the bidirectional DC power converter when operating in mode 3 .

\section{4) Mode 4:}

Fig. 9 shows the equivalent circuit of the bidirectional DC power converter when operating in mode 4 . In this mode, the MOSFETs $\mathrm{Q}_{1}$ and $\mathrm{Q}_{2}$ are all turned off. The energy stored in the supercapacitor bank $\mathrm{C}$ and the inductor $\mathrm{L}$ are released to the batteries B at the same time. In fact, the bidirectional DC power converter acts a boost conversion circuit during this mode. The magnitude of the voltage summation of the supercapacitor bank B and the inductor $\mathrm{L}$ is larger than the batteries B. Therefore, the current I flows into the batteries B via the parasitic diode $\mathrm{D}_{1}$. That means the batteries is charged. The voltage level of the batteries B will rise gradually.

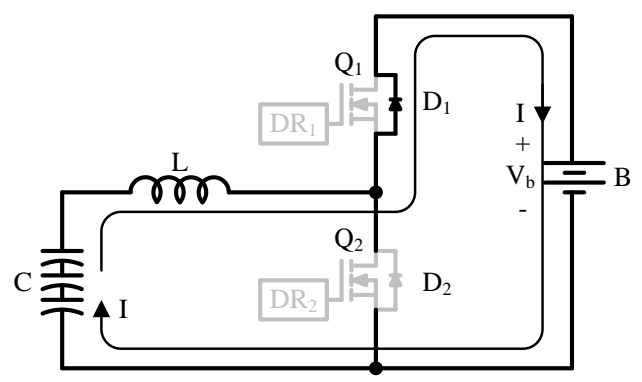

Fig. 9. The equivalet circuit of the bidirectional DC power converter when operating in mode 4.

\section{TEST RESUTS OF THE DEVELOPED BLES}

Fig. 10 shows the prototype of the developed BLES. The microcontroller is an ATMega328 chip. Two MOSFET IRF640s are employed as the switches $\mathrm{Q}_{1}$ and $\mathrm{Q}_{2}$ in the bidirectional $\mathrm{DC}$ power converter. The drivers $\mathrm{DR}_{1}$ and $\mathrm{DR}_{2}$ are TLP250s.

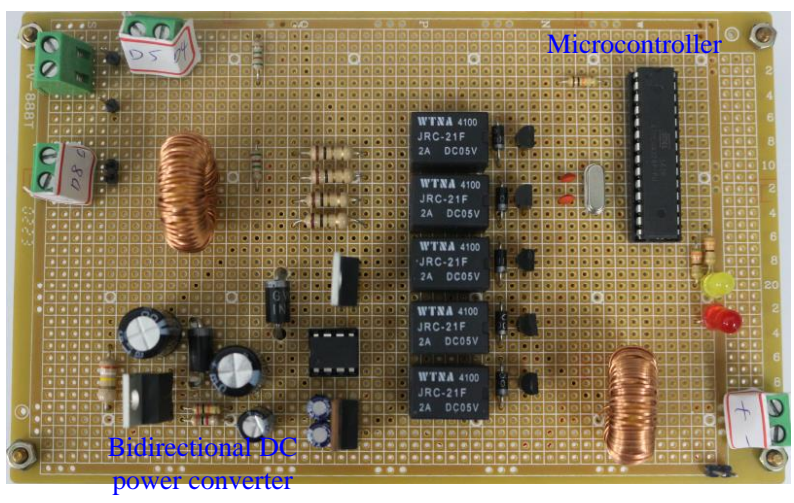

Fig. 10. A photo of the physical circuit of the developed BLES.
In order to examine the performance of the developed BLES, Two test cases were carried out in this research. The batteries in the test cases were two lead-acid batteries with the rating of $12 \mathrm{~V}$ and $4 \mathrm{Ah}$. The supercapacitor bank was composed of three supercapacitors with the rating of $10 \mathrm{~F}$ and 2.7V. The works of the two test cases are described as follows.

Case 1: The bidirectional DC power converter made the batteries to charge the supercapacitor bank. Part of the energy in the batteries was transferred to the supercapacitor bank. The batteries were charged to $12.7 \mathrm{~V}$ beforehand, but the supercapacitor bank was not charged. Test results were recorded at 0,30 , and 60 seconds, respectively.

Case 2: The bidirectional DC power converter made the supercapacitor bank to charge the batteries. The energy in the supercapacitor bank was transferred to the batteries. The initial voltages of the supercapacitor bank and the batteries were $7.29 \mathrm{~V}$ and $12.6 \mathrm{~V}$, respectively. Test results were recorded at 0,30 , and 60 seconds, respectively.

Results of the two test cases are presented and discussed below.

\section{A. Test case 1}

Figs. 11 to 13 show the voltage waveforms of the batteries. The voltages of the batteries gradually reduced from $12.7 \mathrm{~V}$ to $12.0 \mathrm{~V}$. Figs. 14 to 16 show the voltage waveforms of the supercapacitor bank. The voltages of the supercapacitor bank gradually increased from $1.07 \mathrm{~V}$ to $7.44 \mathrm{~V}$. Since the energy of the batteries was transferred to the supercapacitor bank, the voltages of the batteries dropped and the supercapacitor bank rose.

Figs. 17 to 19 show the PWM signal waveforms of the driver DR 1 and Figs. 20 to 22 show the current waveforms of the inductor, respectively. The PWM signals were generated from the microcontroller. The duty cycles of the PWM signals gradually became larger in order to maintain the constant current charging mode. The current of the inductor was the charging current of the supercapacitor bank. The charging currents of the supercapacitor bank at 0,30 , and 60 seconds were kept at approximately $0.5 \mathrm{~A}$. The current waveforms of the inductor were converted to voltage waveforms in this research. Every $100 \mathrm{mV}$ represented $1 \mathrm{~A}$.

\section{B. Test case 2}

Figs. 23 to 25 show the voltage waveforms of the batteries. The voltages of the batteries gradually increased from $12.6 \mathrm{~V}$ to $13.6 \mathrm{~V}$. Figs. 26 to 28 show the voltage waveforms of the supercapacitor bank. The voltages of the supercapacitor bank gradually reduced from $7.29 \mathrm{~V}$ to $2.77 \mathrm{~V}$. These results illustrated that the energy of the supercapacitor bank was surely fed back to the batteries. Therefore, the voltages of the batteries rose and the supercapacitor bank dropped. This situation was contrary to the test case 1 .

Figs. 29 to 31 show the PWM signal waveforms of the driver $\mathrm{DR}_{1}$. The duty cycles of the PWM signals gradually became larger in order to maintain the constant current charging mode. However, the energy stored in the supercapacitor was small. The constant current charging mode could not be kept. Therefore, the duty cycles of the PWM signals were no longer increased after 30 seconds. Figs. 32 to 34 show the current waveforms of the inductor. The current of 
the inductor gradually increased at the beginning of the discharge, but gradually decreased after 30 seconds. The major reason was also that the energy stored in the supercapacitor bank was not enough.

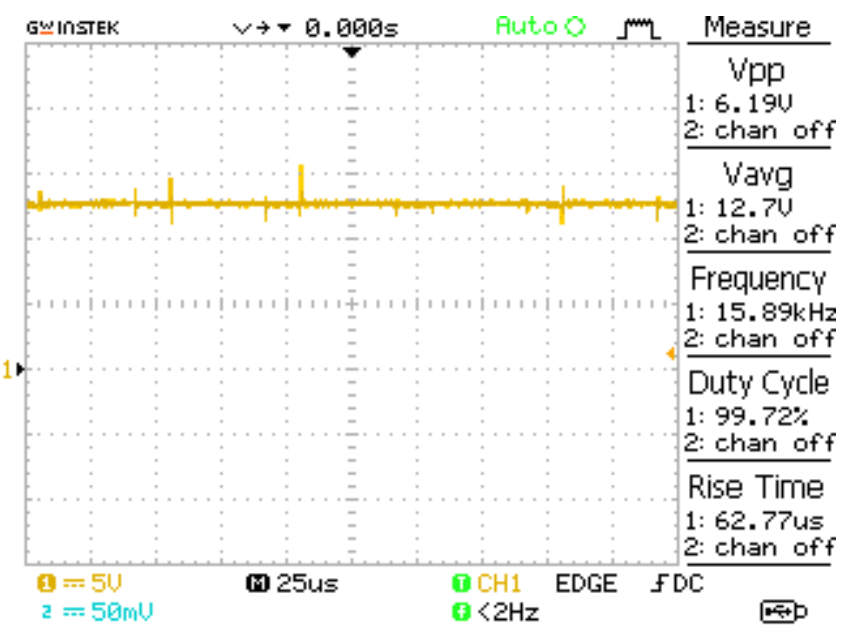

Fig. 11. The voltage waveform of the batteries at 0 second in the test case 1 .

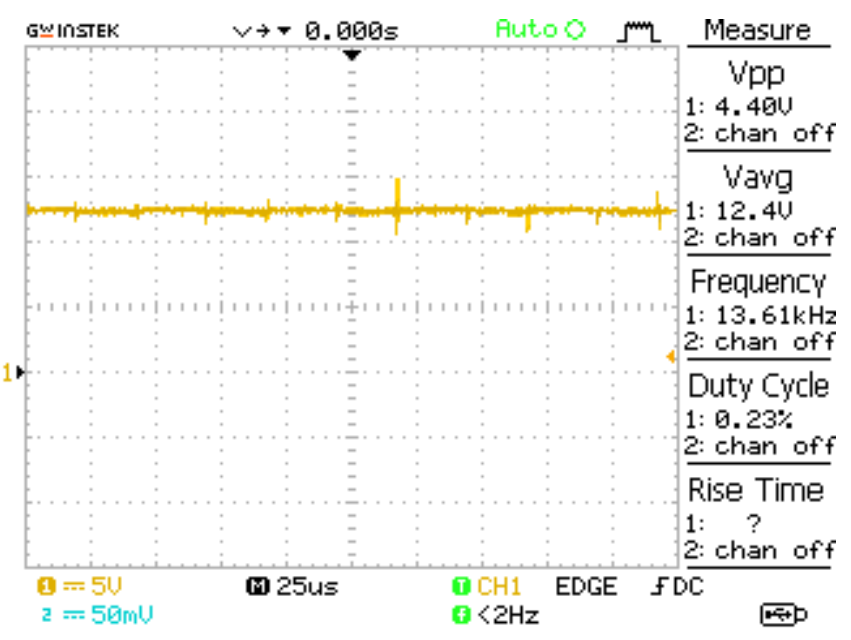

Fig. 12. The voltage waveform of the batteries at 30 second in the test case 1.

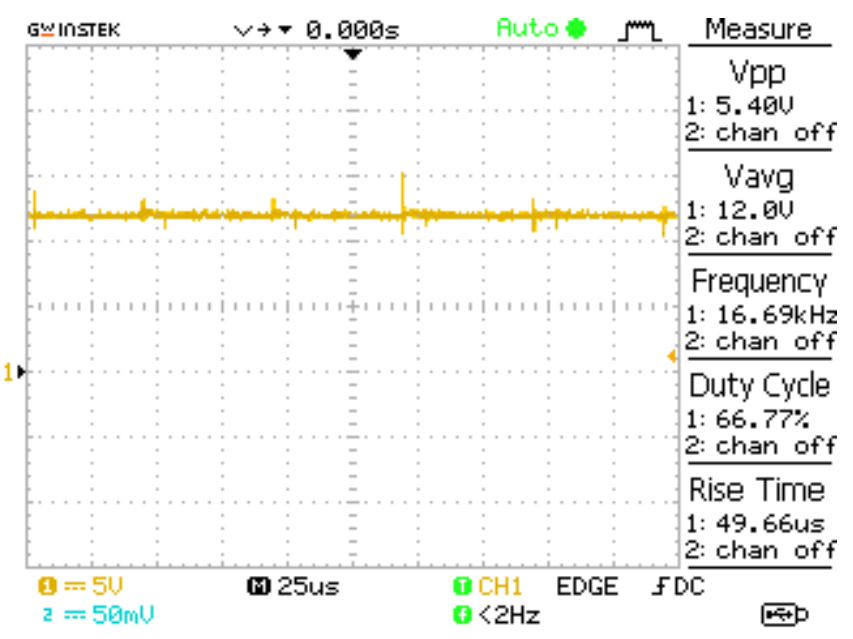

Fig. 13. The voltage waveform of the batteries at 60 second in the test case 1 .

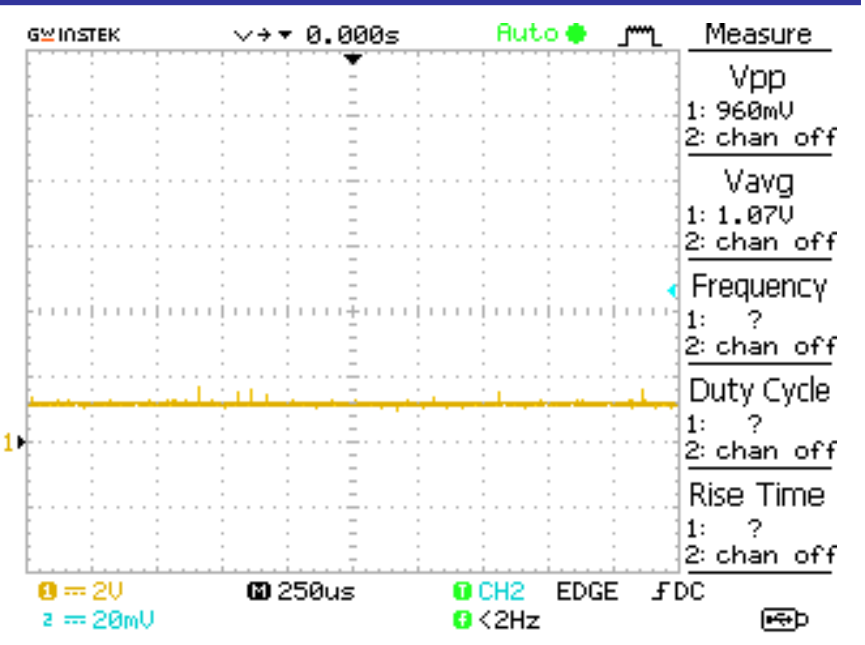

Fig. 14. The voltage waveform of the supercapacitor bank at 0 second in the test case 1 .

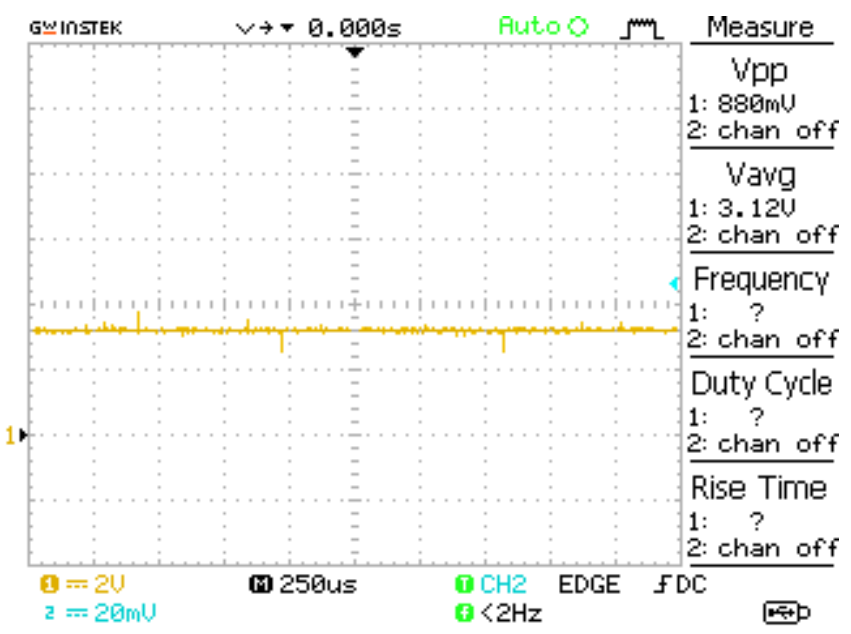

Fig. 15. The voltage waveform of the supercapacitor bank at 30 second in the test case 1 .

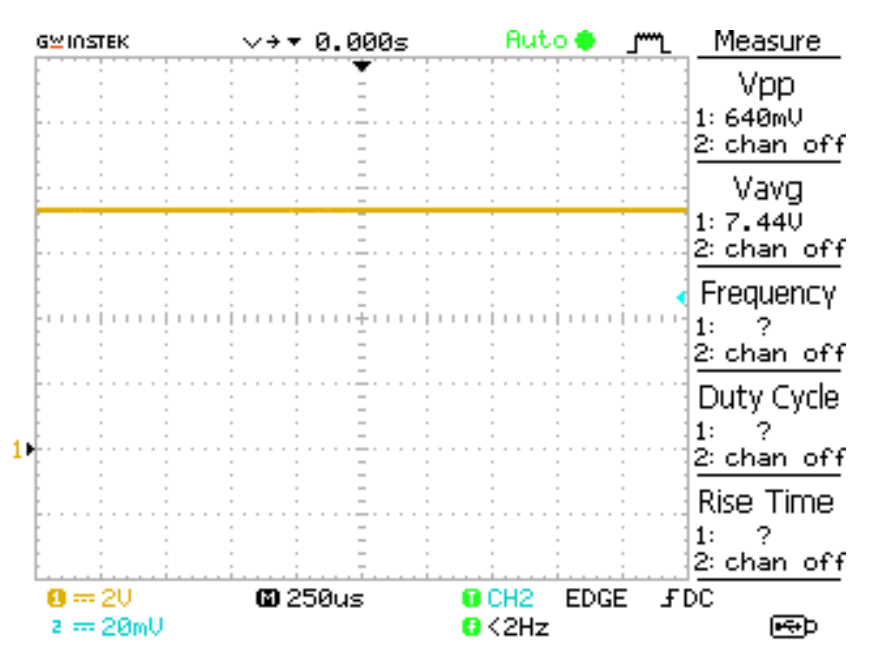

Fig. 16. The voltage waveform of the supercapacitor bank at 60 second in the test case 1 . 


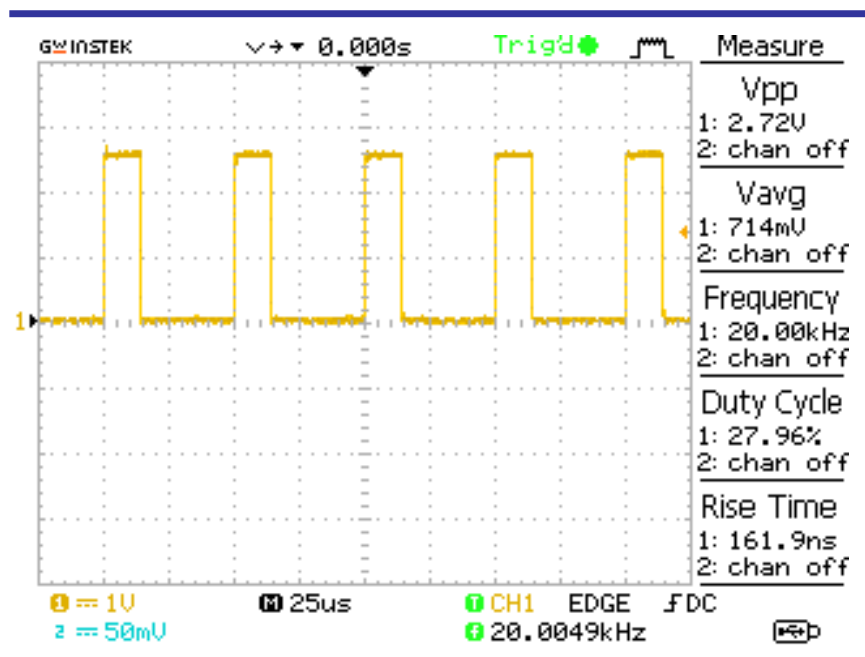

Fig. 17. The PWM signal waveform of driver $\mathrm{DR}_{1}$ at 0 second in the test case 1.

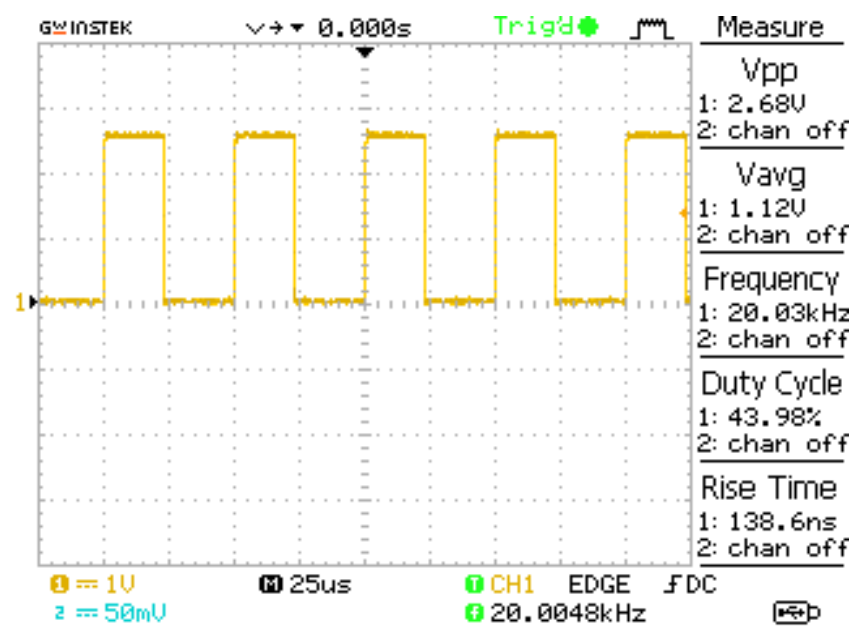

Fig. 18. The PWM signal waveform of driver $\mathrm{DR}_{1}$ at 30 second in the test case 1 .

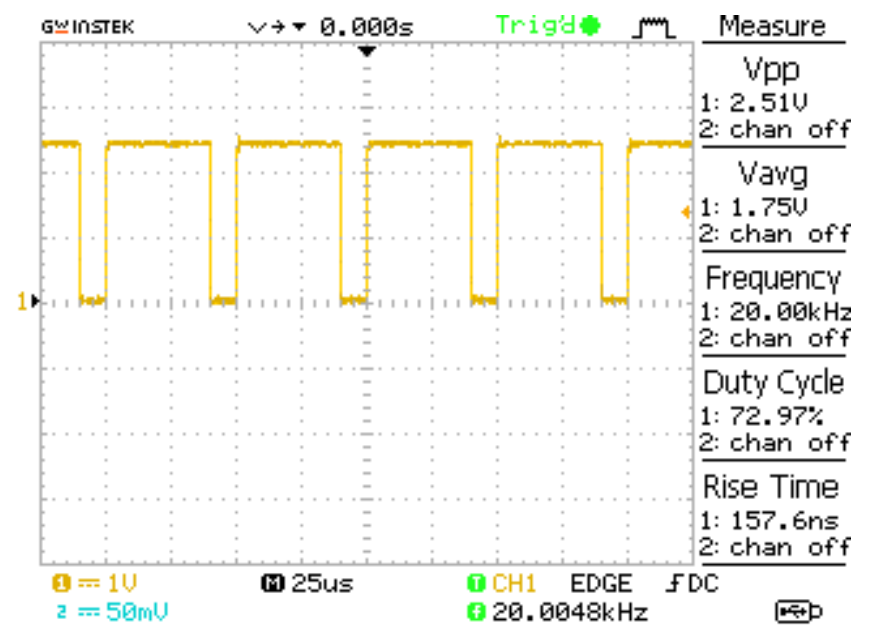

Fig. 19. The PWM signal waveform of driver $\mathrm{DR}_{1}$ at 60 second in the test case 1 .

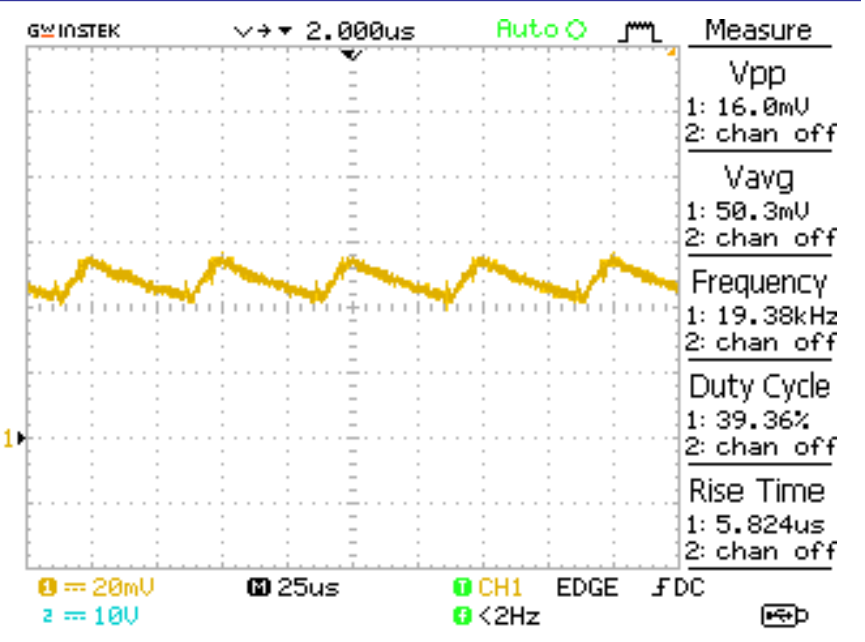

Fig. 20. The current waveform of the inductor at 0 second in the test case 1.

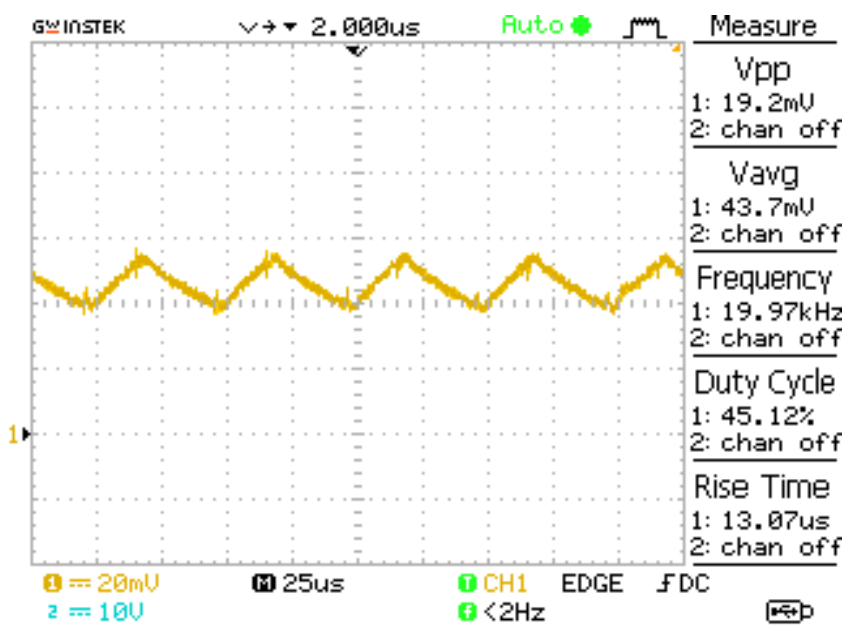

Fig. 21. The current waveform of the inductor at 30 second in the test case 1.

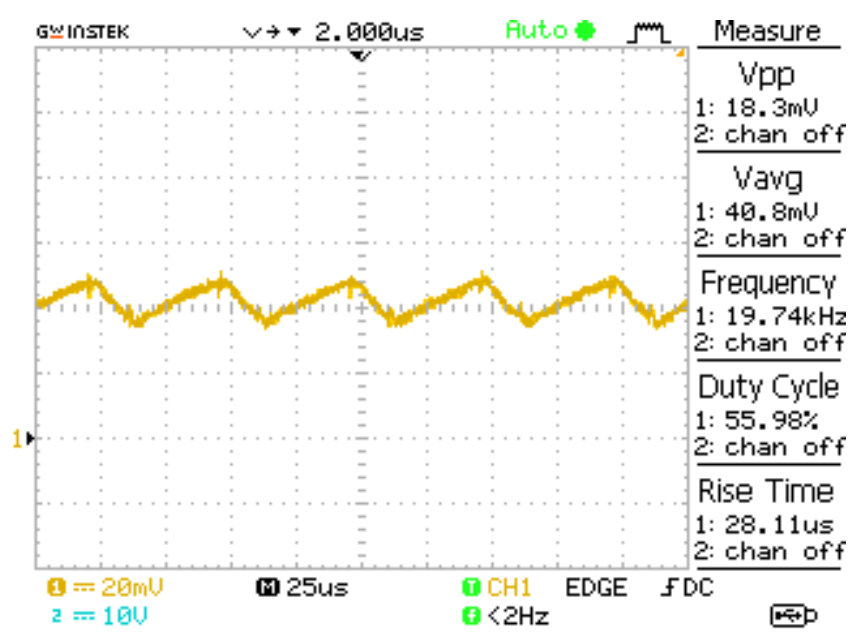

Fig. 22. The current waveform of the inductor at 60 second in the test case 1. 


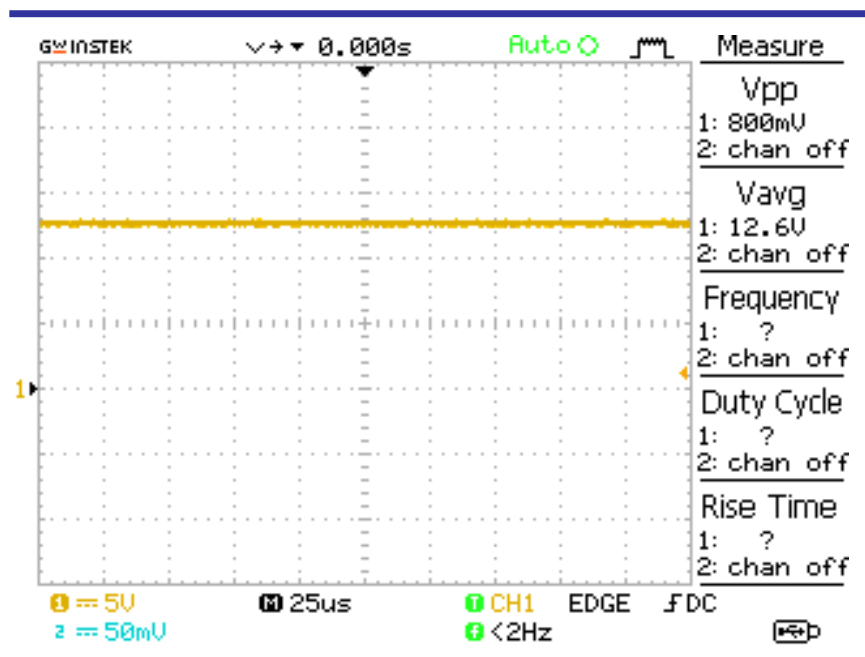

Fig. 23. The voltage waveform of the batteries at 0 second in the test case 2 .

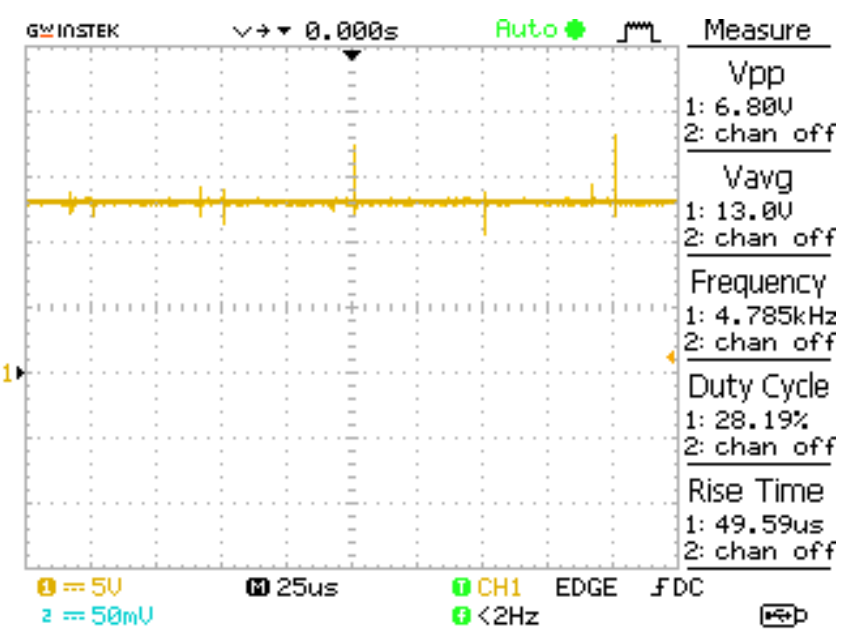

Fig. 24. The voltage waveform of the batteries at 30 second in the test case 2.

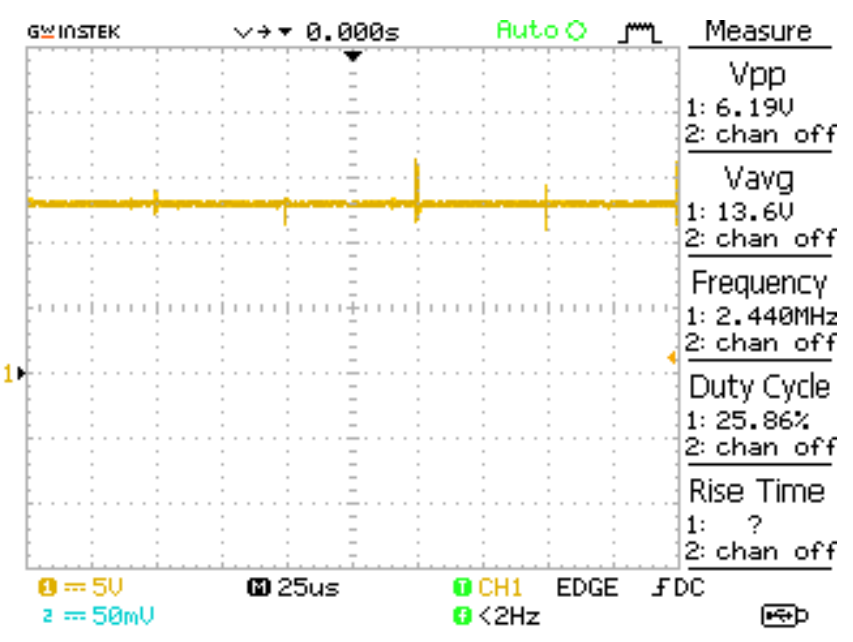

Fig. 25. The voltage waveform of the batteries at 60 second in the test case 2 .

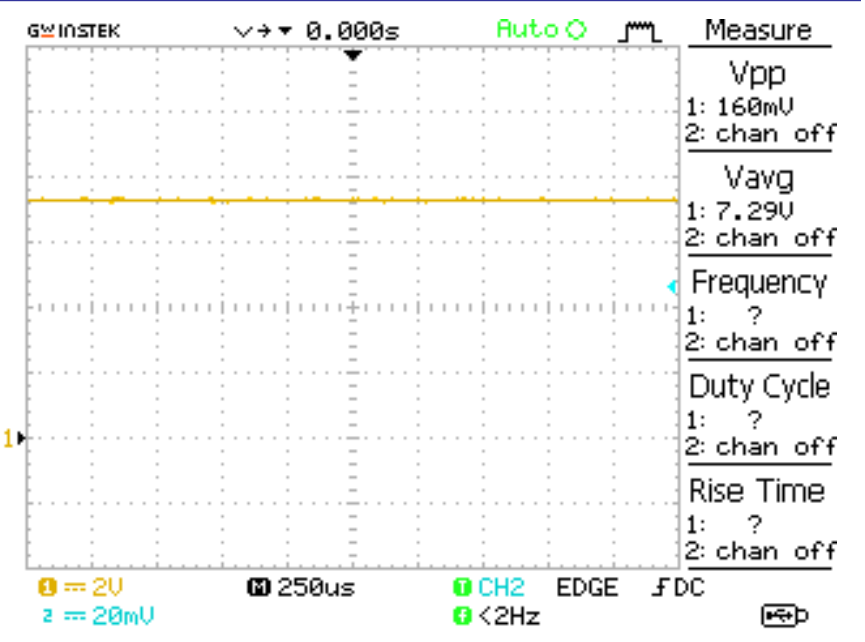

Fig. 26. The voltage waveform of the supercapacitor bank at 0 second in the test case 2 .

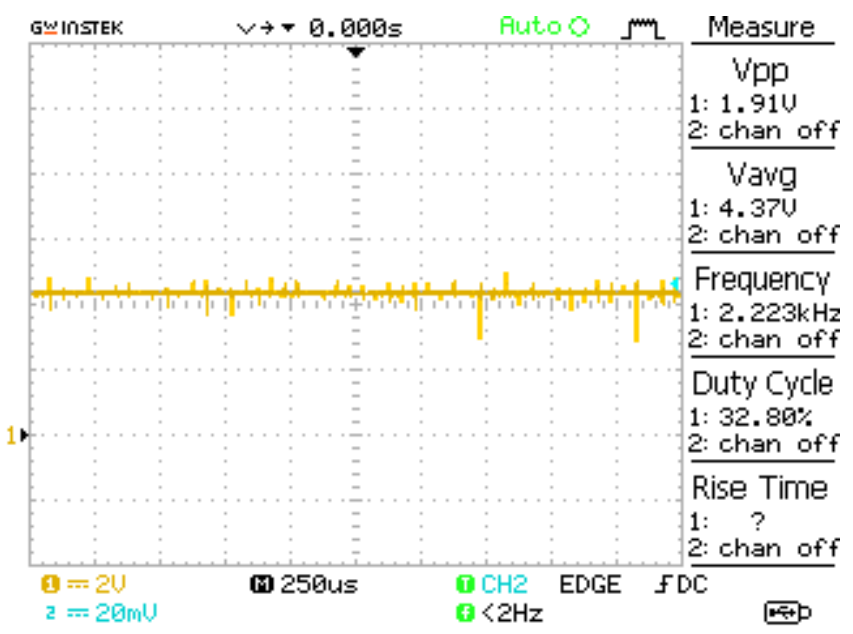

Fig. 27. The voltage waveform of the batteries at 30 second in the test case 2 .

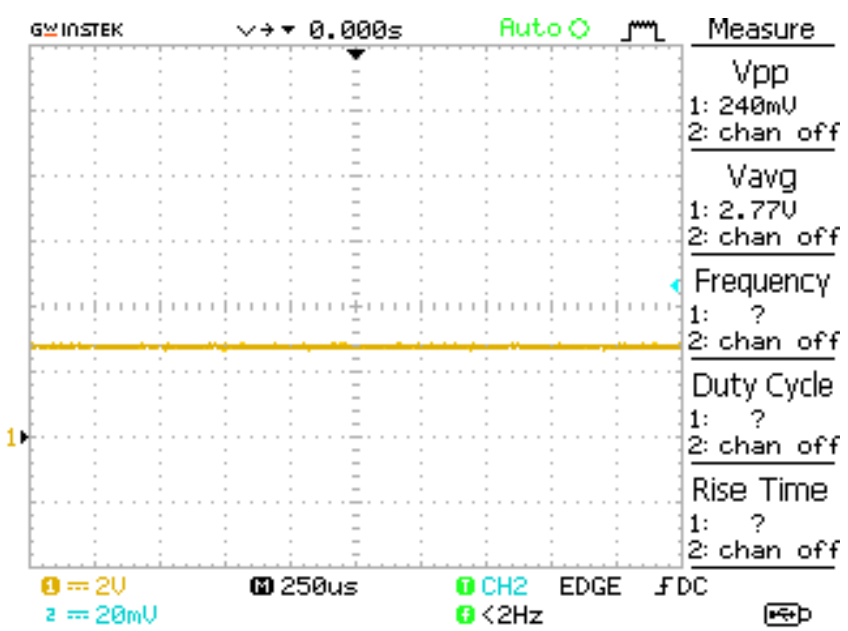

Fig. 28. The voltage waveform of the supercapacitor bank at 60 second in the test case 2 . 


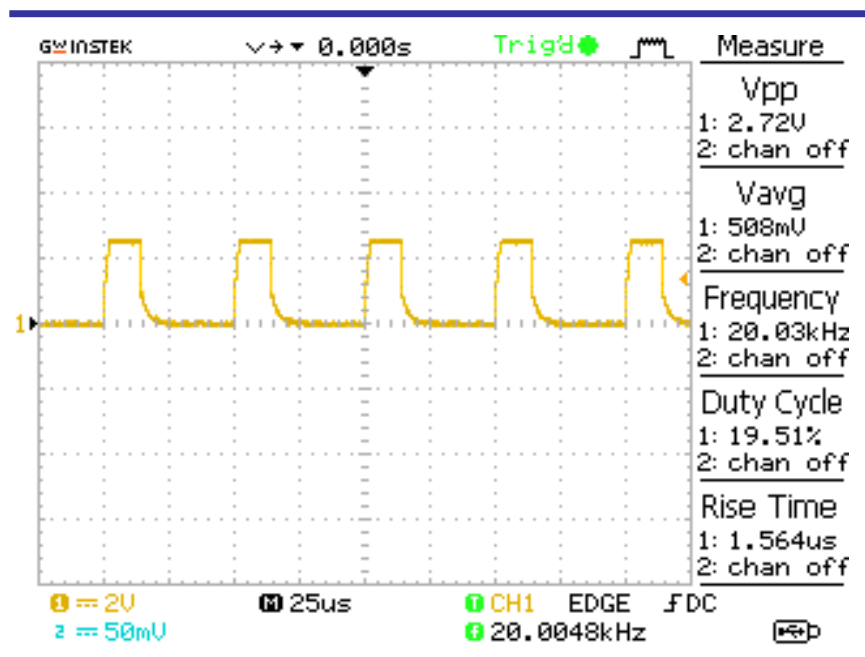

Fig. 29. The PWM signal waveform of driver $\mathrm{DR}_{1}$ at 0 second in the test case 2.

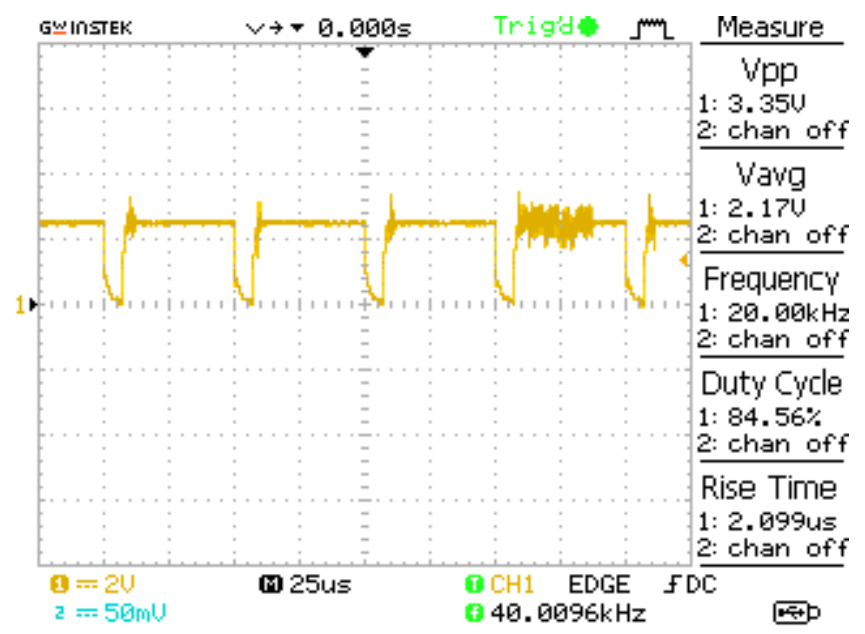

Fig. 30. The PWM signal waveform of driver $\mathrm{DR}_{1}$ at 30 second in the test case 2 .

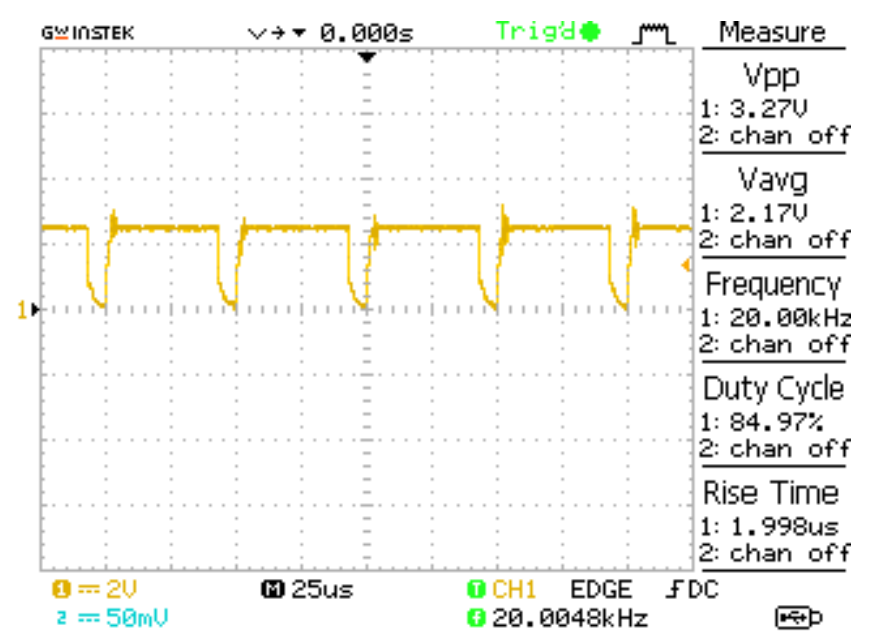

Fig. 31. The PWM signal waveform of driver $\mathrm{DR}_{1}$ at 60 second in the test case 2 .

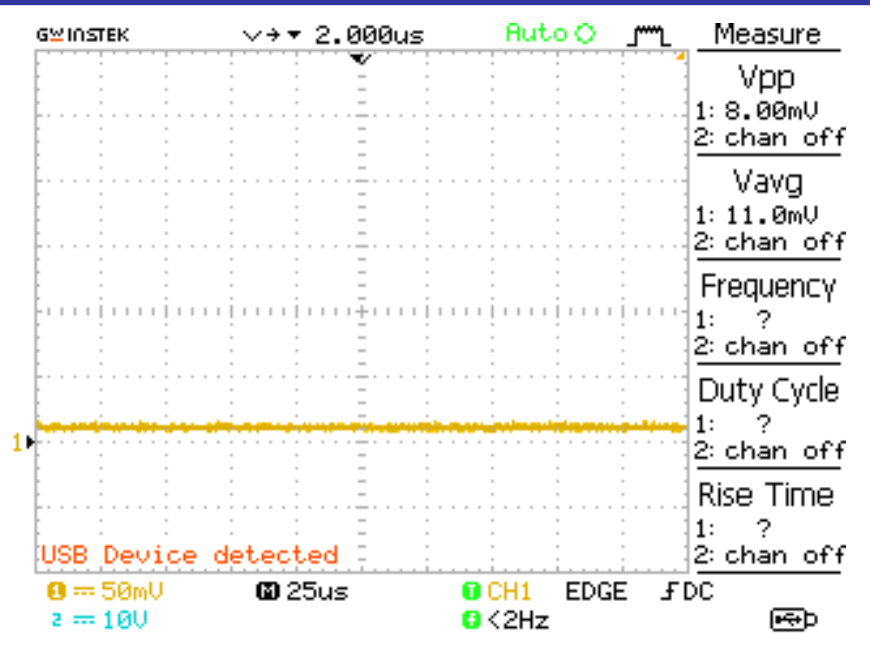

Fig. 32. The current waveform of the inductor at 0 second in the test case 2 .

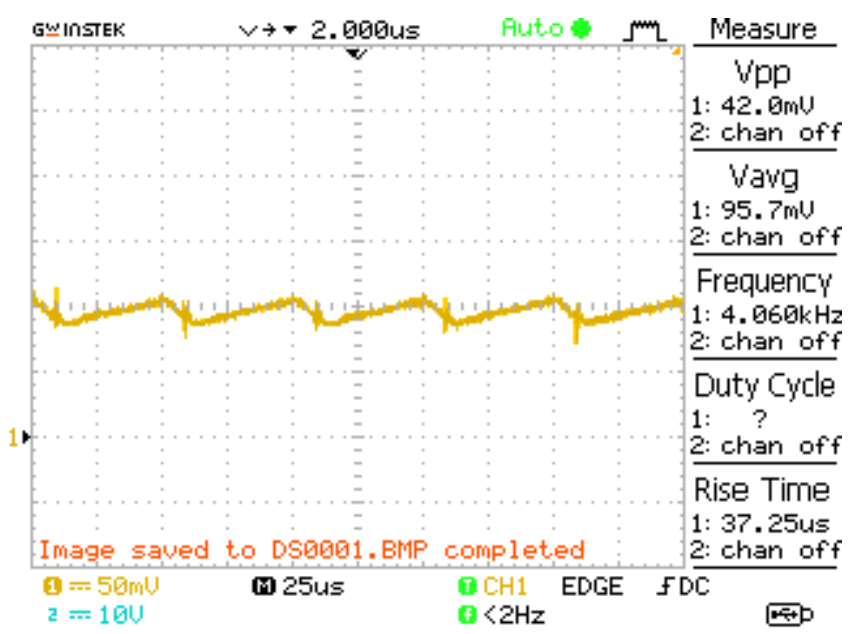

Fig. 33. The current waveform of the inductor at 30 second in the test case 2 .

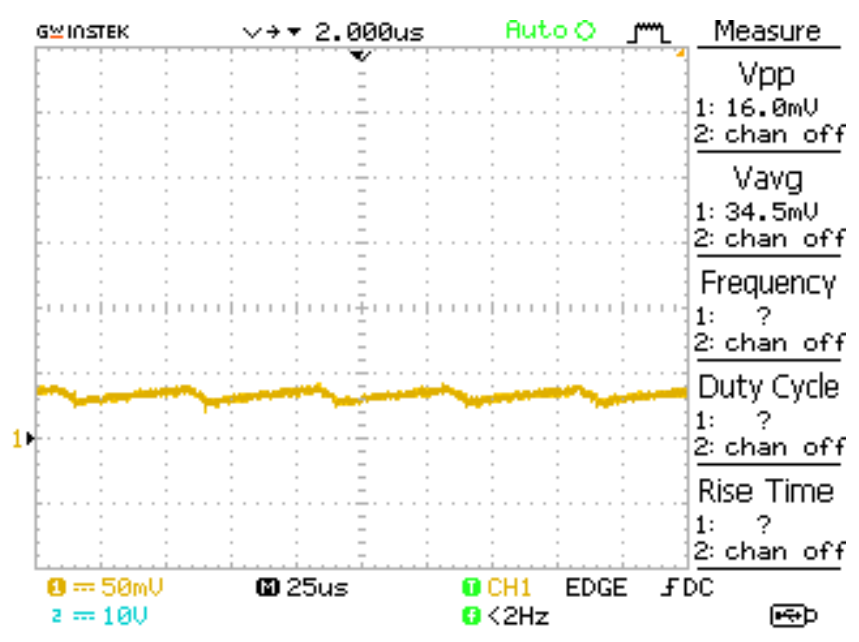

Fig. 34. The current waveform of the inductor at 60 second in the test case 2 . 


\section{CONCLUSIONS}

A battery life extension system (BLES) has been developed by this research. The BLES allows the UPSs' batteries and a supercapacitor bank to periodically charge and discharge each other via a bidirectional DC power converter. Therefore, the energy storage materials of UPSs' batteries can be activated effectively and the life time of the batteries can be increased. The development of the bidirectional DC power converter in the BLES is based on a half-bridge conversion topology. Its conversion efficiency can reach $90 \%$. Since the use of supercapacitors to store the energy of the batteries in UPSs, the developed BLES can increase the batteries' life time by more than $20 \%$.

Batteries are important components in UPSs. If a battery is fully charged for a long time, but rarely are discharged. The life time of the battery will be shortened. This situation will reduce the benefits of the UPS and increase the maintenance cost for the users $[8,9]$. Therefore, the batteries in UPSs should be discharged periodically. The BLES is developed for this purpose. It is useful for industries and environment protection.

\section{ACKNOWLEDGMENT}

This research was founded by a grant provided by the Ministry of Science and Technology, Taiwan, R.O.C., under the grant number: MOST 107-2813-C-149-004-E.

\section{REFERENCES}

[1] V. K. Bussa, R. K. Singh and R. Mahanty, "Minimum phase hybrid boost converter for smart residential uninterruptible power supply system," IEEE Transportation Electrification Conference, pp. 1-5, December 2017.

[2] K. Shi, X. Wang, D. Dong, C. Hu and D. Xu, "Unified control scheme design for both the PWM rectifier and the inverter in the uninterruptible power supply (UPS) system," IEEE $3^{\text {rd }}$ International Future Energy Electronics Conference and ECCE Asia, pp. 1462-1467, June 2017.

[3] M. Aamir, K. A. Kalwar and S. Mekhilef, "Review: uninterruptible power supply (UPS) system," ELSEVIER Renewable and Sustainable Energy Reviews, vol. 58, pp. 1395-1410, May 2016.

[4] A. Ali, S. M. Asghar, R. K. S. Abdul, J. M. Yaqoob, H. Abdul and K. M. Usman, "Impact of wide-spread use of uninterruptible power supplies on Pakistan's power system," ELSEVIER Energy Policy, vol. 98, pp. 629-636, Novenber 2016.

[5] C. Zhang, J. M. Guerrero, J. C. Vasquez and E. A. A. Coelho, "Control architecture for parallel-connected inverters in uninterruptible power systems," IEEE Transactions on Power Electronics, vol. 31, issue. 7, pp. 5176-5188, July 2016.

[6] R. Marius, Z. Ping, L. Dinsheng, I. Dan and P. Mircea, Multiphysics Simulation by Design for Electrical Machines, Power Electronics and Drives, Wiley-IEEE Press: Newyork, 2017, pp.253-263.

[7] D. W. Hart, Power Electronics, McGraw-Hill Education: Newyork, 2010, pp.287-290.

[8] V. Apetrei, C. Filote and A. Graur, "The analysis of the deforming regime generated by AC-DC converters using discrete wavelet transform," WSEAS Transactions on Systems, vol. 13, pp. 551-559, 2014.

[9] A. M. Munoz, J. J. G. Rosa, J. M. F. Arias, F. J. B. Outerino and A.G Castro, "Energy efficiency criteria in uninterruptible power supply selection," ELSEVIER Applied Energy, vol. 88, Issue. 4, pp. 13121321, April 2011. 